\title{
In vivo imaging reveals sigmoidal growth kinetic of $\beta$-amyloid plaques
}

\author{
Steffen Burgold ${ }^{1,2}$, Severin Filser ${ }^{1,2}$, Mario M Dorostkar ${ }^{1,2}$, Boris Schmidt ${ }^{4}$ and Jochen Herms ${ }^{1,2,3^{*}}$
}

\begin{abstract}
A major neuropathological hallmark of Alzheimer's disease is the deposition of amyloid plaques in the brains of affected individuals. Amyloid plaques mainly consist of fibrillar $\beta$-amyloid, which is a cleavage product of the amyloid precursor protein. The amyloid-cascade-hypothesis postulates $A \beta$ accumulation as the central event in initiating a toxic cascade leading to Alzheimer's disease pathology and, ultimately, loss of cognitive function. We studied the kinetics of $\beta$-amyloid deposition in Tg2576 mice, which overexpress human amyloid precursor protein with the Swedish mutation. Utilizing long-term two-photon imaging we were able to observe the entire kinetics of plaque growth in vivo. Essentially, we observed that plaque growth follows a sigmoid-shaped curve comprising a cubic growth phase, followed by saturation. In contrast, plaque density kinetics exhibited an asymptotic progression. Taking into account the fact that a critical concentration of $A \beta$ is required to seed new plaques, we can propose the following kinetic model of $\beta$-amyloid deposition in vivo. In the early cubic phase, plaque growth is not limited by $A \beta$ concentration and plaque density increases very fast. During the transition phase, plaque density stabilizes whereas plaque volume increases strongly reflecting a robust growth of the plaques. In the late asymptotic phase, A $\beta$ peptide production becomes rate-limiting for plaque growth. In conclusion, the present study offers a direct link between in vitro and in vivo studies facilitating the translation of A $\beta$-lowering strategies from laboratory models to patients.
\end{abstract}

Keywords: Alzheimer's disease, $\beta$-amyloid, Aggregation kinetics, Plaque growth, Two-photon imaging, In vivo

\section{Introduction}

Alzheimer's disease $(\mathrm{AD})$ is the most common form of dementia and is characterized by the accumulation of amyloid plaques as one major neuropathological hallmark [1]. Amyloid plaques consist mainly of $A \beta$ peptide $(A \beta)$ that is produced by sequential cleavage of amyloid precursor protein (APP) by $\beta$-secretase and $\gamma$-secretase [2]. The amyloidcascade-hypothesis postulates that $A \beta$ accumulation is the central event in the etiology of $\mathrm{AD}$, initiating a toxic cascade that culminates in widespread neurodegeneration [3-6]. Indeed, recent biomarker studies in humans have shown that changes in $A \beta$ metabolism and $A \beta$ accumulation initiate about 20 years before the onset of clinical symptoms [7-10].

\footnotetext{
* Correspondence: Jochen.Herms@med.uni-muenchen.de

${ }^{1}$ German Center for Neurodegenerative Diseases (DZNE),

Ludwig-Maximilians-University Munich, Feodor-Lynen-Str. 23, 81377

Munich, Germany

${ }^{2}$ Center for Neuropathology, Ludwig-Maximilians-University Munich,

Feodor-Lynen-Strasse 23, 81377 Munich, Germany

Full list of author information is available at the end of the article
}

Cloning of the amyloid precursor protein pioneered the investigation of $A \beta$ aggregation in vitro [11]. Monomers of $A \beta$ were shown to form higher order aggregates in a time and concentration dependent manner [12]. The process of in vitro $A \beta$ aggregation, as well as $A \beta$ accumulation in humans, with time follows a sigmoidal curve shape $[7,13,14]$.

In recent years several studies investigated the kinetics of $\mathrm{A} \beta$ aggregation into amyloid plaques in $\mathrm{AD}$ mouse models [15]. Collectively, these studies revealed that newly formed plaques were initially very small and enlarged slowly over long periods of time during the early stages of amyloid pathology [16-20], while late-stage amyloid pathology lacked further plaque formation $[17,19,21]$ and growth $[16,17,20,22]$.

In the present study we aimed at extending this basic knowledge of in vivo plaque growth kinetics by investigating the close relationship between plaque density and plaque growth. Furthermore, we were able to monitor the complete plaque growth kinetics over an observation 
period of 15 months that reflect both the early and late stage amyloid pathology. In this manner, we found that plaque growth follows an initial cubic and a late asymptotic phase.

\section{Materials and methods Transgenic mice}

Heterozygous Tg2576 [9] mice (B6;SJL-Tg(APPSWE) 2576Kha from Taconic, Cologne, Germany) were kindly provided by neuroanatomy group of Abbott (Ludwigshafen, Germany). Tg2576 mice express a human APP with the Swedish mutation (K670M/N671L) under a hamster prion protein promoter. Heterozygous APPPS1 mice coexpress a human APP with the Swedish mutation and a mutated PS1 (L166P) under the neuron-specific Thy1-promoter [23]. Mice were of both sexes (four females in the young cohort and one male/three females in the old cohort) and grouphoused under pathogen-free conditions until surgery, after which they were single-housed. All procedures were performed in accordance with an animal protocol approved by the University of Munich and the Government of Upper Bavaria [Az. 55.2-1.54-2531-110-06].

\section{Cranial window surgery}

A cranial window was implanted over the right cortical hemisphere as previously reported [24-27]. In short, the mice were anesthetized with an intraperitoneal injection of ketamine/xylazine $(0.13 / 0.01 \mathrm{mg} / \mathrm{g}$ body weight; WDT/ Bayer Health Care, Garbsen/Leverkusen, Germany). Additionally, dexamethasone $(0.02 \mathrm{ml}$ at $4 \mathrm{mg} / \mathrm{ml}$; Sigma) was intraperitoneally administered immediately before surgery [28]. A circular piece of the skull (about $5 \mathrm{~mm}$ in diameter) over the right hemisphere (centered over the parietal bone, approx. $5.5 \mathrm{~mm}$ caudal from the bregma and $5.5 \mathrm{~mm}$ lateral from midline) was removed using a dental drill (SchickTechnikmaster C1; Pluradent; Offenbach, Germany). The craniotomy was closed immediately with a round coverslip (5 $\mathrm{mm}$ in diameter), held with dental acrylic. A small metal bar, containing a hole for a screw, was glued next to the coverslip to allow repositioning of the mouse during subsequent imaging sessions. After surgery, mice received subcutaneous analgesic treatment with carprophen $(7.5 \mathrm{mg} / \mathrm{kg}$ body weight; Rimadyl; Pfizer, New York, USA) and antibiotic treatment with cefotaxim $(0.25 \mathrm{mg} / \mathrm{g}$ body weight; Pharmore, Ibbenbüren, Germany).

\section{Long-term two-photon in vivo imaging}

Imaging started 3 to 4 weeks after the cranial window preparation to allow the animals to recover from surgery. For amyloid staining methoxy-X04 [29] was intraperitoneally injected $24 \mathrm{~h}$ before imaging. Initially, we administered a loading dose of $2 \mathrm{mg} / \mathrm{kg}$ body weight and in subsequent weekly imaging sessions a maintenance dose of $0.4 \mathrm{mg} / \mathrm{kg}$ body weight [17]. Two-photon imaging was performed on a LSM 7 MP (Zeiss, Jena, Germany) equipped with standard photomultiplier detectors and a 20x water-immersion objective (W Plan-Apochromat 20x/1.0 DIC, 1.0 NA, Zeiss, Jena, Germany). Methoxy-X04 was excited at $750 \mathrm{~nm}$ by a Ti:Sa laser (MaiTai DeepSee, Spectra-Physics, Darmstadt, Germany) and emission was collected from 440 to $500 \mathrm{~nm}$. Image stacks of $850 \times 850 \times 250-400 \mu^{3}$ were acquired using the "tilescan" mode of the microscope control software (Zen2009/Zen2010 64bit) that performs automatic stitching of several fields of view $(2 \times 2$ were used) with a lateral resolution of $0.83 \mu \mathrm{m}$ and $3 \mu \mathrm{m}$ separation distance between consecutive images. Mice were anesthetized with isoflurane (Forene ${ }^{\oplus}$, Abbott, Wiesbaden, Germany) for imaging and fixed to a custom-made holder using the glued metal plate. In subsequent imaging sessions, previously imaged volumes were identified by eye using the unique blood vessel pattern and fine adjusted by the positions of preexisting plaques. This allowed a precise alignment of the same imaging volume over a period of up to 15 months. The laser intensity was adjusted to keep the emitted fluorescence stable at different depths using the $\mathrm{z}$ correction tool in the microscope control software and also at subsequent imaging sessions.

The following volumes were imaged: young cohort $2.888 \mathrm{~mm}^{3}$ (12 positions), old cohort $3.111 \mathrm{~mm}^{3}$ (16 positions), 12 to 18 months $1.076 \mathrm{~mm}^{3}$ (4 positions) and 12 to 27.5 months $0.559 \mathrm{~mm}^{3}$ (2 positions). The following numbers of plaques were analyzed for each imaging cohort: 50 newly formed and 101 preexisting plaques (12 to 14 months), 786 plaques (18 to 20 months) and 90 plaques (12 to 27.5 months).

\section{Image processing}

The images with data depth of 12 bit were analyzed as time series of three-dimensional (3D) images in Imaris (Versions 6.2.1/7.4.2, Bitplane, Zurich, Switzerland). First, images were contrast-normalized (i.e., based on the average and standard deviation of intensities of 3D stacks). Plaque volumes were extracted by 3D-surface-rendering with background subtraction and a threshold of 500. All detected plaques were tracked by utilizing a custom-written Matlab plugin for Imaris or the surface tracking module of Imaris. Newly formed plaques were tracked back to the first time point when they appeared and were only assessed when present for at least 3 time points. Kinetic volume data were exported as Excel files. 3D stacks are either displayed as 3D-volume-rendered images ("normal shading" algorithm, Imaris) or as 3D-surface-rendered images in figures. Only the image data of detected plaques are shown in figures to focus the viewer's eye on the essential information within the images. Background signals from autofluorescence were removed whereas contrast settings within time series were kept constant. 


\section{Data analysis and statistics}

For each plaque the radii from each time point were calculated from the kinetic volume data assuming a spherical shape of plaques [19]. Plaque densities were calculated for each imaged position. All other calculations, curve fitting and graphs were done in Prism (Version 5.04, GraphPad, La Jolla, USA). Data were tested for normality using D'Agostino-Pearson omnibus K2 test. Plaque densities and sizes had log-normal distributions and were therefore logarithmized which allowed for parametric statistical testing. These data were displayed with an "antilog" scale to represent the real measurement dimensions. For each plaque a linear growth rate was determined as the slope of a linear regression from radii calculations over time. Linear plaque growth rates were not normally distributed. All statistical tests are specified in the figure legends.

\section{Results}

Long-term in vivo imaging over 15 months reveals sigmoid-shaped plaque growth kinetics

Tg2576 mice express human amyloid precursor protein with the Swedish mutation under the control of a hamster prion protein promoter [9], leading to the accumulation of A $\beta$-peptide and deposition of amyloid plaques starting at 8 to 10 months of age $[9,30]$. The fluorescent marker methoxy-X04 was injected [29] to visualize fibrillar amyloid through open-skull cranial windows over long time periods. We imaged two different cohorts starting at 12 and 18 months of age over at least 2 months, in weekly intervals (Figure 1a). These time-frames were chosen since plaque development is very dynamic in the young cohort whilst being more static in the older mice $[17,22]$. The mice from the young cohort were imaged for as long as technically feasible, limited by the clarity of the cranial window, in order to reconcile the measurements within both age cohorts in a single time series (Figure 1a). For precise measurement of the plaque density and in order to maximize the number of analyzable plaques, big volumes that typically sized $850 \times 850 \times 250-400 \mu^{3}$ ( $x, y, z$ dimensions $)$ were scanned to 27.5 months (Figure 1b; see Additional file 1 for the complete time series and the Material and Methods section for all integrated volumes of each cohort). All images were of optimal quality and did not suffer from motion artifacts due to breathing or heart beating of the animal. The volume of plaques and cerebral amyloid angiopathy (CAA) were assessed by 3D surface-rendering and tracked over time. This analysis revealed a nonlinear sigmoid-shaped curve for the mean $\left(R^{2} 0.983\right.$, Figure 1c) and also integrated volume $\left(R^{2} 0.988\right.$, Figure $\left.1 \mathrm{~d}\right)$ of plaques. The integrated volume of the CAA followed a sigmoid function, too $\left(R^{2} 0.952\right.$, Figure 1e). In contrast, the plaque density kinetics exhibited an asymptotic progression and could be fitted to a one-phase association function $\left(\mathrm{R}^{2}\right.$ 0.975, Figure 1d).
Next, we analyzed the growth kinetics for each individual plaque separately, rather than the mean of all plaques as previously (Figure 2). We found that single plaque kinetics could also be fitted into a sigmoid function (Figure 2a,b). A comparison of all fitted curves for each individual plaque (originating from the example in Figure 1b) highlighted the fact that only a few plaques became very large whereas the majority of plaques showed much flatter curves with slower $\mathrm{A} \beta$ accumulation (Figure $2 \mathrm{c}$ ).

\section{Quantification of plaque densities, sizes and growth rates in young and aged mice}

The differences in plaque densities, sizes and growth rates between the young and old age cohorts are summarized in Figure 3. Mean plaque density started very low in the young cohort at $26.2 \mathrm{~mm}^{-3}\left(13.8-49.8 \mathrm{~mm}^{-3} \mathrm{CI}\right)$, but increased to $42.0 \mathrm{~mm}^{-3}\left(23.2-75.7 \mathrm{~mm}^{-3} \mathrm{CI}\right)$ during the 2 -month observation period (Figure $3 a, b)$. This robust increase in plaque density was attributed to 50 newly formed plaques that were added to the 101 already-existing plaques at the beginning of the study. In contrast, within the old cohort only 3 new plaques were observed alongside 786 preexisting plaques. As expected, mean plaque density was significantly higher at 18 months of age $\left(191 \mathrm{~mm}^{-3}\right.$; 126-292 $\mathrm{mm}^{-3} \mathrm{CI}$ ) compared to 12 and 14 months of age (Figure $3 \mathrm{~b})$. Long-term imaging revealed no further significant increase in mean plaque density, which peaked at a plateau of $160 \mathrm{~mm}^{-3}\left(100-255 \mathrm{~mm}^{-3} \mathrm{CI}\right)$ at 24 months of age (Figure 3c, solid line).

The size of a plaque can be represented by its radius, calculated from the measured volume assuming a spherical plaque shape to facilitate comparisons [19]. At 12 months, newly-formed plaques had a mean radius of $2.27 \mu \mathrm{m}(2.12-2.43 \mu \mathrm{m} \mathrm{CI}$; Figure 3d), while the mean radius of preexisting plaques was $5.08 \mu \mathrm{m}(4.45-5.80 \mu \mathrm{m}$ $\mathrm{CI})$. With ageing, mean plaque radii increased further and reached $7.98 \mu \mathrm{m}$ at 14 months $(7.31-8.72 \mu \mathrm{m} \mathrm{CI}), 10.8 \mu \mathrm{m}$ at 18 months $(10.4-11.2 \mu \mathrm{m} \mathrm{CI})$ and $16.7 \mu \mathrm{m}$ at 27 months (Figure 3d, 15.0-18.6 $\mu \mathrm{m} \mathrm{CI}$ ). Radii from newly formed plaques showed the narrowest spectrum and were exclusively normally distributed, while sizes from preexisting plaques covered a wide range and had a log-normal distribution (Figure 3e).

A linear regression of plaque radii over time revealed linear growth rates reflected by the slope of the lines [19]. Nascent plaques exhibited the fastest median growth rate at $0.475 \mu \mathrm{m} /$ week (Figure 3f, 0.326-0.589 $\mu \mathrm{m} /$ week interquartile range, IQR). Preexisting plaques from the young cohort grew at almost the same rate $(0.326 \mu \mathrm{m} /$ week, 0.217-0.479 $\mu \mathrm{m} /$ week IQR; Figure 3f), while the old cohort had the slowest growth rate $(0.099 \mu \mathrm{m} /$ week, -0.070 $0.262 \mu \mathrm{m} /$ week IQR; Figure 3f). Nevertheless, an overall net growth could be detected even in the old cohort (Figure 3g). 


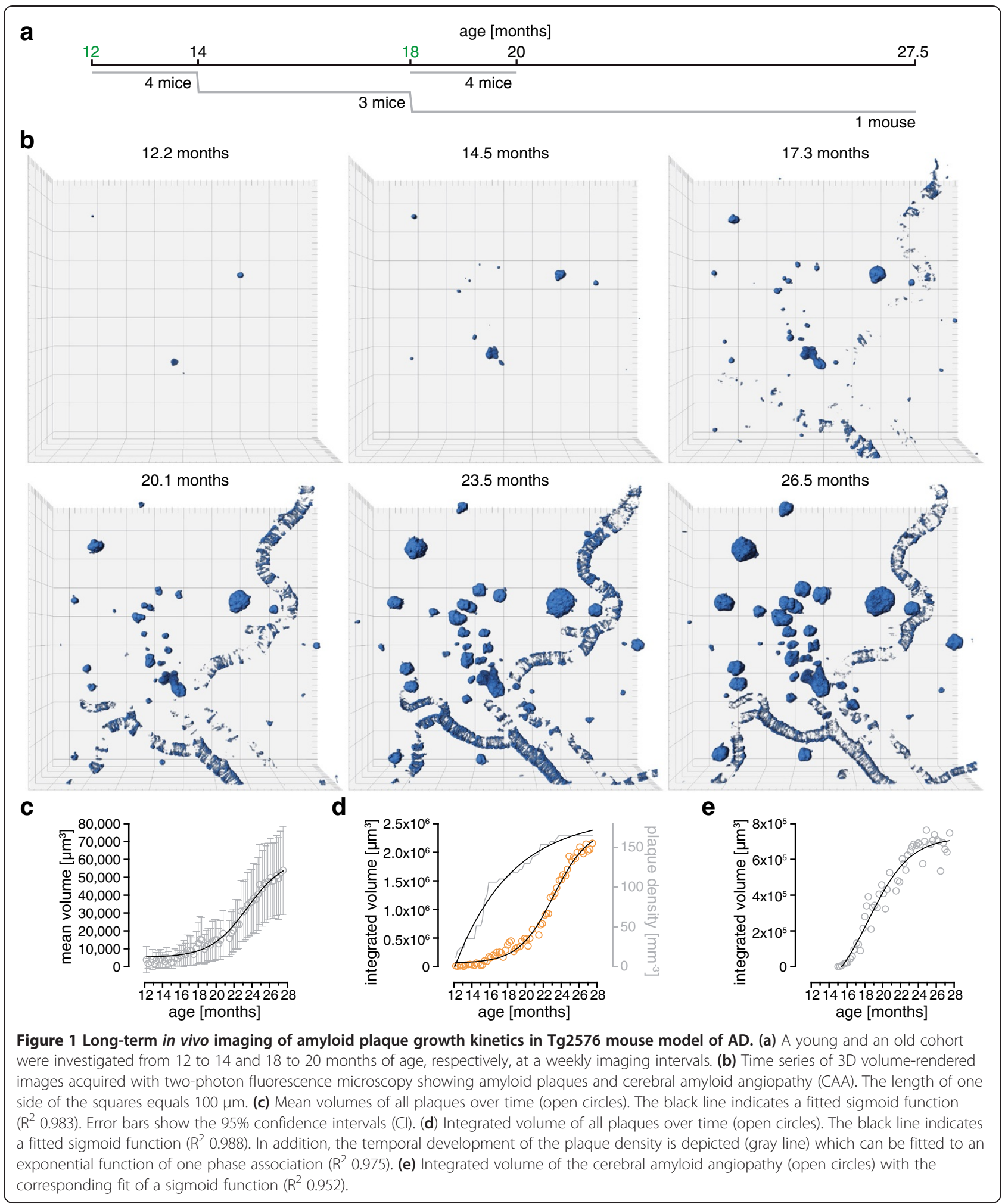

As the long-term data over 15.5 months displayed both phases (cubic and asymptotic) of growth a bifid analysis of the growth rates was performed to compare them to the young and old cohorts (Figure 4a). The cubic and asymptotic growth phases are divided by the inflection point of the fitted sigmoid function that lies at the age of 23.5 months. Therefore, plaque growth rates were determined from 12 to 23.3 and from 23.5 to 27.5 months of 


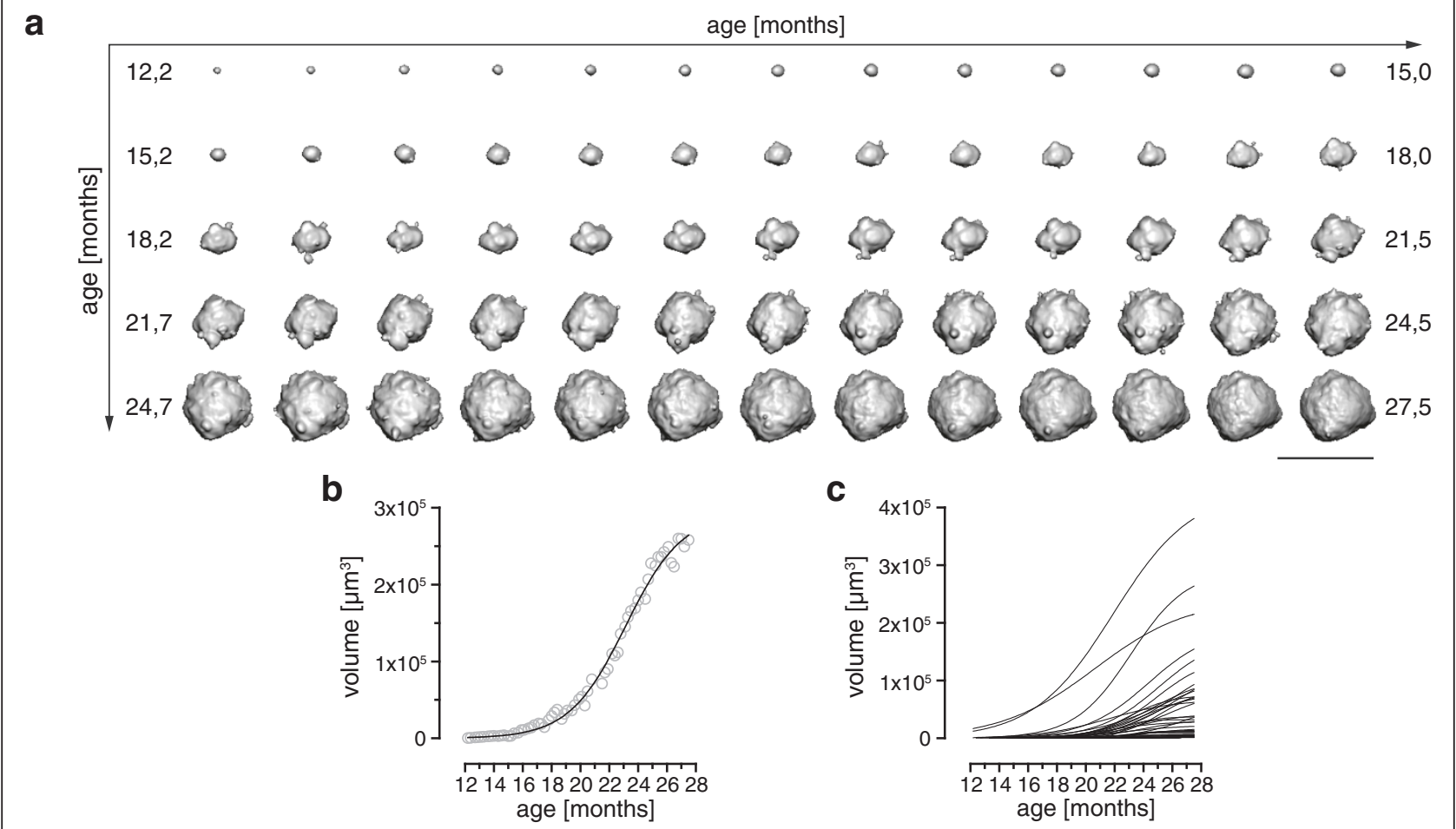

Figure 2 Illustration of a single plaque over the whole imaging period of $\mathbf{1 5 . 5}$ months. (a) Time series of a single plaque as a surface-rendered object as derived from 3D image analysis. Scale bar represents $100 \mu \mathrm{m}$. (b) Volume from the plaque shown in (a) over time (open circles) with the corresponding fit of a sigmoid function (black line). (c) Sigmoid fits of plaque volumes of all imaged plaques in one mouse. Note the considerable variance in plaque volumes.

age for each single plaque (Figure $4 \mathrm{~b})$. The linear plaque growth rate was fastest in the cubic phase (median $0.365 \mu \mathrm{m} /$ week, 0.258-0.453 $\mu \mathrm{m} /$ week IQR), whereas a strong decline was observed for the asymptotic phase (Figure 4c, median 0.159, 0.049-0.297 $\mu \mathrm{m} /$ week IQR).

\section{Characteristic relationships between quantitative plaque parameters}

Relationships between plaque densities, growth rates, size and age at plaque formation were analyzed to enable a detailed characterization of plaque formation and growth. In the early stage of plaque pathology (young cohort) plaque density at the start of imaging correlated with plaque formation rate, the latter being an indicator of the number of plaques formed per volume and time unit (Figure 5a). The average plaque formation rate in the young cohort amounted to 3.40 week $^{-1} \mathrm{~mm}^{-3}$ (1.635.16 week $^{-1} \mathrm{~mm}^{-3} \mathrm{CI}$ ). A global comparison of all data collected in the young and old cohort revealed an inverse correlation between averaged plaque growth rates and plaque densities (Figure 5b). In addition, analysis of a single plaque over a period of 15.5 months covering the dynamic cubic and the asymptotic phases of plaque development provided further insight into plaque growth characteristics. The largest plaques at the end of imaging had formed early during plaque development, which leads to a strong inverse correlation between plaque radius and age of the mouse at plaque formation (Figure $5 \mathrm{c}$ ). Moreover, plaque radius at the end of imaging correlated strongly with the corresponding growth rates of these plaques (Figure $5 \mathrm{~d}$ ).

There was a wide distribution of individual plaque growth rates which lead to the question whether there is a specific spatial relationship between growth rates of neighboring plaques. This analysis was performed using data from long-term imaging, the main reason being that a longer observation period facilitates more precise measurements of plaque growth rates. For a visual impression, plaques from overview image of Figure $1 \mathrm{~b}$ were categorized in five classes according their growth rates. These plaques were displayed as 3D surfacerendered objects with their corresponding growth rate class coded in different colors (Figure 6a). Analysis involved calculating the shortest Euclidean distance of a plaque to its nearest neighbor, which averaged $65.8 \mu \mathrm{m}$ (55.3-78.4 $\mu \mathrm{m}$ CI; Figure $6 \mathrm{~b})$. In the case of a spatial relationship, growth rates of neighboring plaques would be expected to be similar. The analysis of two imaged positions and 46 pairs of plaques (90 plaques total), however, revealed no such relationship (Figure 6c). Moreover, the differences between growth rates of neighboring plaques 


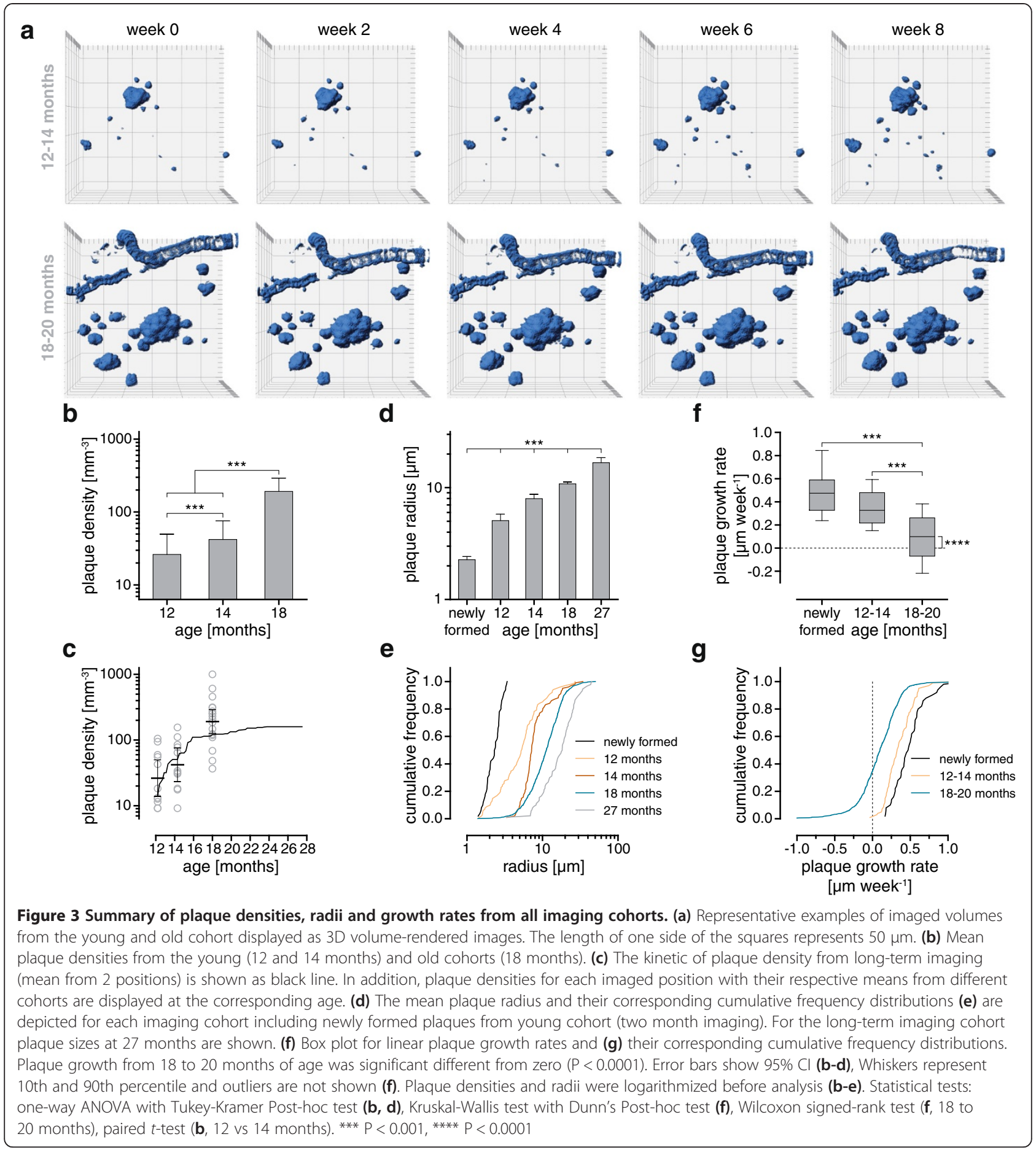

showed a wide distribution and reflect the visual impression from Figure 6 a.

\section{Discussion}

Novel insights into plaque growth kinetics arose from several in vivo studies in recent years. Assessment of basic plaque growth parameters in the present study gave results consistent with the majority of findings from the literature. The most prominent feature is the increase of plaque size during ageing [16-20,31]. Plaques in their nascent stage were smallest and constituted a distinct size class that showed a normal distribution. Preexisting plaques were much larger, depending on the age of the mice, and displayed a log-normal distribution as also found in humans [32]. In contrast, the rate of plaque growth decreased with ageing $[16,17,20,22]$. Several reasons could 


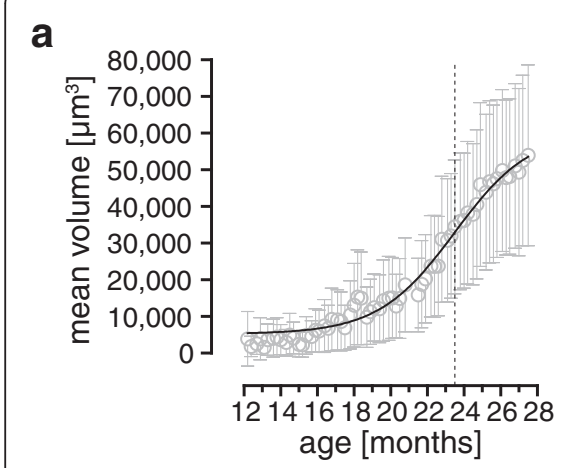

b

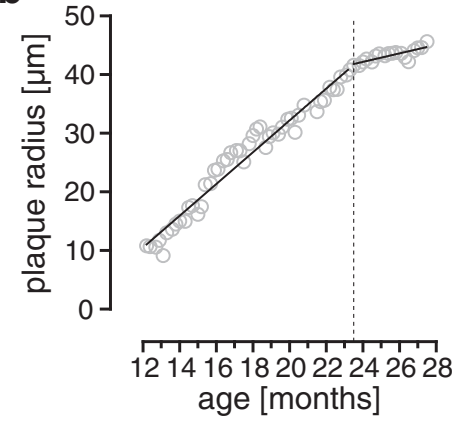

c

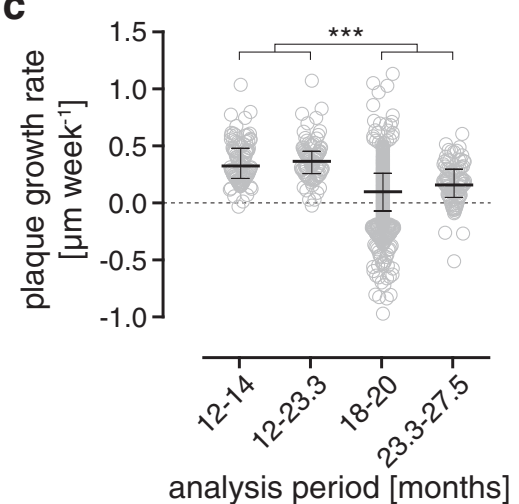

Figure 4 Bifid analysis of the plaque growth data of long-term imaging. (a) Mean volume over time (error bars, 95\% Cl). A sigmoid function was fitted to the mean volume (black line). The dotted line indicates the inflection point of the fitted curve dividing the cubic and asymptotic parts of the function. (b) Kinetics of plaque radii. According to the cubic and asymptotic phase of volume growth two linear regressions (black lines) were fit from 12 to 23.3 and 23.5 to 27.5 months of age. This analysis was done for each single plaque. (c) Comparison of the plaque growth rates resulting from the bifid analysis with the values gained from the young and old imaging cohort. Black lines with error bars show medians with interquartile range. Multiple comparisons were performed by Kruskal-Wallis test with Dunn's Post-hoc test. ***P $<0.001$
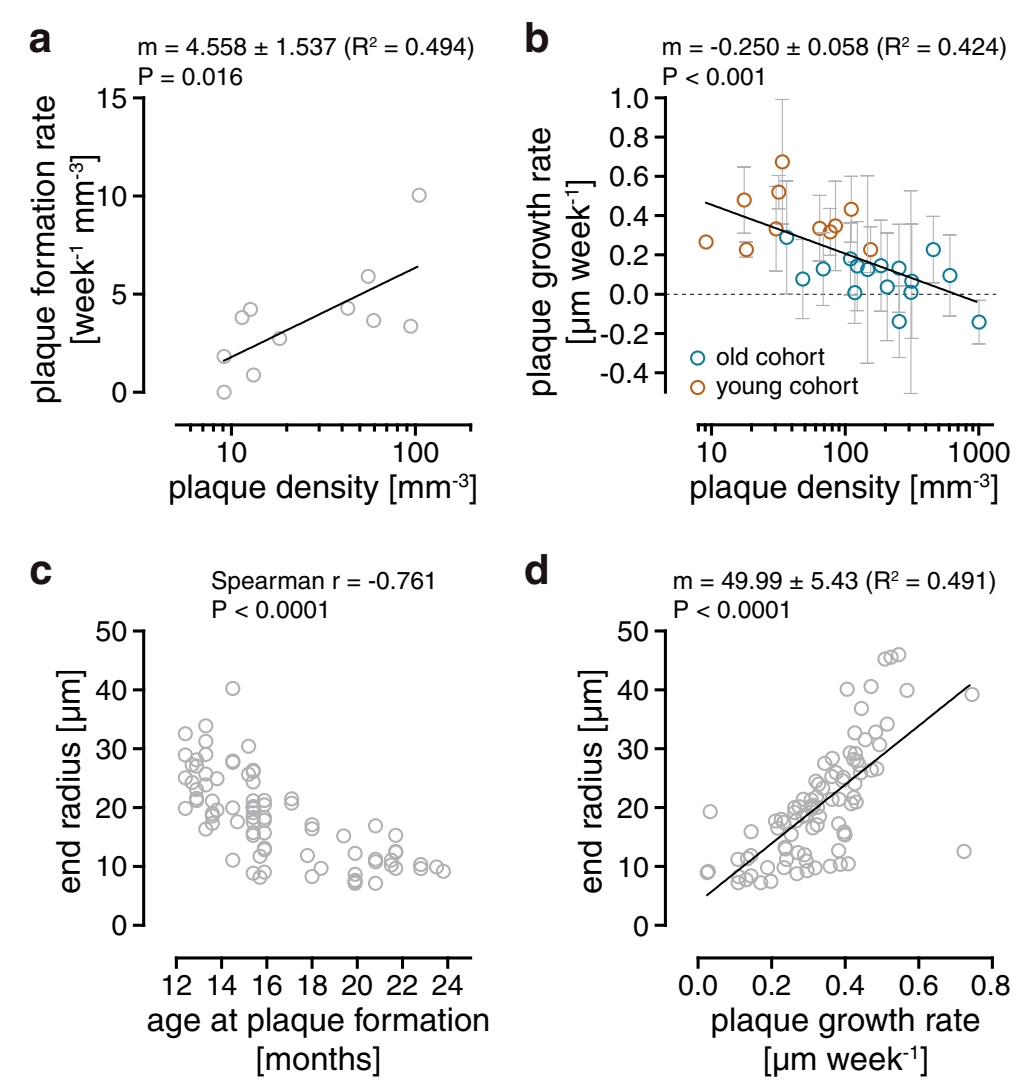

Figure 5 Correlations between quantitative parameters of plaque growth dynamics. (a) Plaque formation rate as a function of plaque density. Black line, linear regression (slope is significantly different from zero, $p=0.016$ ). Each circle represents one imaged position. (b) Plaque growth rate as a function of plaque density. Error bars show the $95 \% \mathrm{Cl}$. Black line shows a linear regression of the data. The slope is statistically significant different from zero ( $p<0.001$ ). (c) Radius of newly formed plaques at the end of long-term imaging over 15.5 months as a function of the age of the mouse at plaque formation ( $N=81$ newly formed plaques from 2 positions). (d) Plaque radius at the end of long-term imaging over 15.5 months as a function of plaque growth rate ( $N=90$ newly formed and preexisting plaques). Black line shows a linear regression of the data. The slope is statistically significant different from zero. Statistical tests: F-test (a, b, d), Spearman correlation (c). 
a

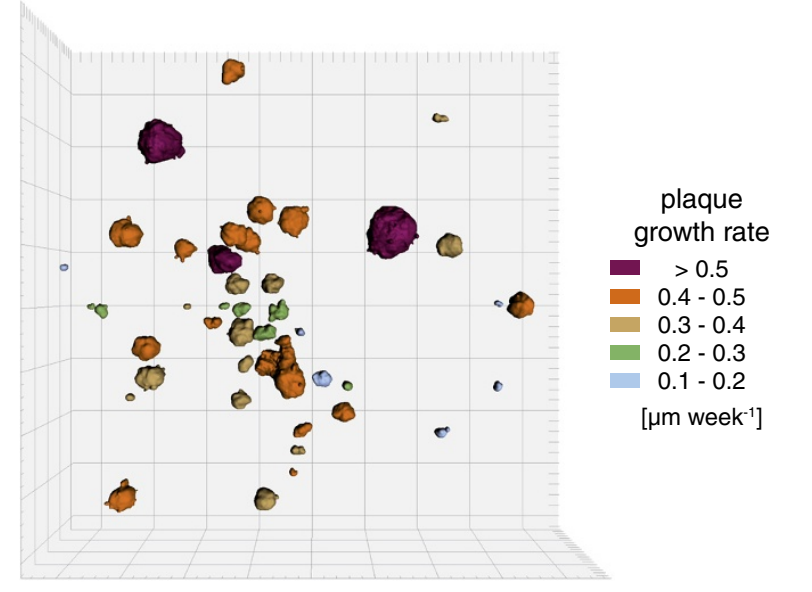

b

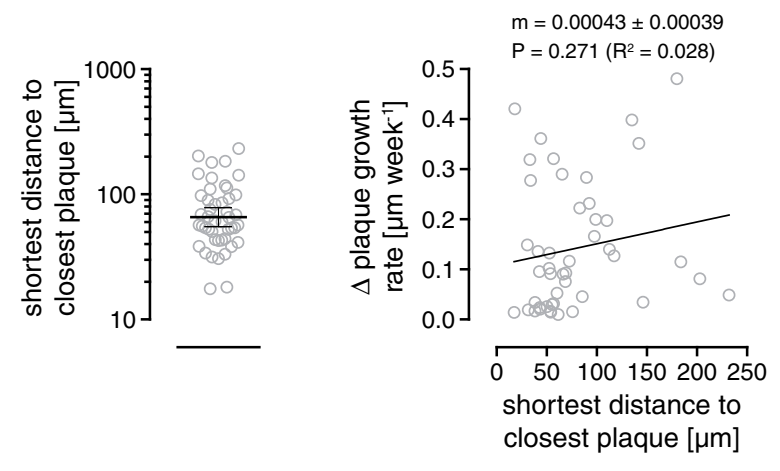

Figure 6 Spatial relationship between growth rates of neighboring plaques. (a) Amyloid plaques are displayed as 3D volume-rendered images. Plaque growth rates are color-coded according to a classification into 5 bins. One square represents $100 \mu \mathrm{m}$. (b) Shortest distance to the closest neighboring plaque (90 plaques), calculated from the long-term imaging over 15.5 months. The shortest distances are displayed in the graph with the mean and $95 \% \mathrm{Cl}(65.8 \mu \mathrm{m}, 55.3-78.4 \mu \mathrm{m} \mathrm{Cl})$. (c) For each pair of nearest neighbor plaques the difference between their linear plaque growth rates and their shortest distance were calculated (open circles). No relationship between both parameters could be measured by linear regression. The slope was not statistically significant different from zero. Statistical test: F-test (c).

be responsible for the decline in plaque growth: (i) $A \beta$ production becomes rate limiting, because an everincreasing total surface area of $\beta$-amyloid plaques requires an increase in the amount of $A \beta$ to maintain a constant linear growth rate. (ii) The dissociation of $A \beta$ aggregates from $\beta$-amyloid plaques increases. (iii) The number and volume of microglia around plaques increases and changes plaque maintenance [33]. In addition, the arguments (ii) and (iii) may explain negative plaque growth rates in aged animals, whereas we can not completely exclude that at least in part data noise is responsible for negative values. A recent study proposed clustering of plaques as different mechanism of plaque growth [34]. In some rare instances we also observed fusion of plaques which we found as a consequence of their volume growth in combination with close proximity to each other (see image series Figures 1 and 3, Additional file 1). Furthermore, two studies found no steady plaque growth $[17,19,21]$ or plaque growth and shrinkage [33] in the early phase of plaque development. Possible reasons for the inconsistent findings are discussed within the literature and beyond the scope of this publication [16-20].

For the first time we were able to chart the entire kinetics of growth of a single plaque, and demonstrate a sigmoidal growth curve comprising both a cubic and an asymptotic phase (Figures 1 and 2, Additional file 2: Figure S1a-b). Recent studies in humans using positron emission tomography (PET) applying an amyloid tracer (Pittsburgh compound $\mathrm{B}, \mathrm{PiB})[10,35,36]$ also found a plateau and/or a sigmoid-shaped progression of $\beta$-amyloid accumulation $[7,13]$.
Long-term imaging over at least 6 months revealed an asymptotic increase in plaque densities that could be fitted to a one-phase association function. This finding is congruent with a previously described decline in the rate of plaque formation with ageing [16-20,31]. Interestingly, plaque growth and plaque density are inter-related, as shown by correlation analysis of both parameters.

During the dynamic phase of plaque development (young cohort) a distinct correlation between plaque density and plaque formation rate was observed. In humans, a similar relationship was found using PiB-PET which revealed a higher increase in $\mathrm{PiB}$ retention in the second PET scan after 18 months if those subjects had a positive $\mathrm{PiB}$ signal in the first PET scan [37]. Fibrillization of $\mathrm{A} \beta$ has been convincingly shown by in vitro studies to consist of a two-step process that requires first the nucleation of a seed, before polymerization into amyloid fibrils $[14,38]$. Furthermore, a direct relationship was measured in vitro between $A \beta$ concentration and the ability to form nucleation seeds $[8,39]$. For a mouse model of $A D$, a similar correlation between $A \beta$ concentration in the interstitial/ cerebrospinal fluid and plaque load (a relative measure of the area of a brain slice that is covered by plaques) was reported [40,41]. Taking together the knowledge from these studies with our results, a link between plaque density and $A \beta$ production can be established since there is a strong correlation between plaque density and plaque load (Additional file 2: Figure S1c). Interestingly, plaque densities varied over a wide range which suggests that $A \beta$ production varies between individual Tg2576 mice a fact that was already reported 
[42]. A possible reason could be the mixed genetic background of $\operatorname{Tg} 2576$ mice which may be lead to differences in epigenetic regulation and/or promotor activities [9]. Nevertheless, all 4 animals of the young cohort covered the complete range of plaque densities measured in 30 animals of a further study (Additional file 2: Figure S1d). In addition, the predictive value of plaque density regarding $\mathrm{A} \beta$ production could be limited in mouse models without a constant $A \beta$ production over time [23]. Another limitation worth noting is that methoxy$\mathrm{X} 04$ in mice, and also $\mathrm{PiB}$ in humans, detect insoluble fibrillar but not soluble A $\beta$ species $[29,36,43,44]$. Furthermore, in vivo two-photon imaging using methoxyX04 allows for the resolution of single amyloid plaques in brain regions accessible by this technique while PET imaging allows to image the whole brain, but with a resolution limit of about $1 \mathrm{~mm}^{3}$.

The observation of a steady linear increase in plaque radius over several months during the cubic growth phase presumes that $A \beta$ concentration is not rate limiting. Otherwise a decline in growth would be expected due to the ever-increasing surface area of $\beta$-amyloid plaques which requires a proportional increase in the amount of $\mathrm{A} \beta$ to maintain a constant linear growth rate. A comparison of plaque growth of the Tg2576 with the APPPS1 mouse model that was investigated by two other studies, using exactly the same methods and data analysis, supports this hypothetical assumption [16-20,31]. Although APPPS1 mice produce much more $\mathrm{A} \beta$ and accumulation starts much earlier than in $\operatorname{Tg} 2576$ mice $[9,19,23,30]$ median plaque growth rates were about $0.3 \mu \mathrm{m} /$ week in both mouse models [16-20,31]. In conclusion, there appears to be an upper limit for median plaque growth in vivo that was also identified in vitro for the growth of $A \beta$ fibrils [45]. The higher $A \beta$ production in APPPS1 mice causes a much higher plaque density compared to Tg2576 mice $\left(631 \mathrm{~mm}^{-3}, 521-762 \mathrm{~mm}^{-3} \mathrm{CI}\right.$ vs. $26.2 \mathrm{~mm}^{-3}, 13.8-49.8 \mathrm{~mm}^{-3} \mathrm{CI}$, Additional file 2: Figure S1e, Figure 3b). Accordingly, a 10-fold higher rate of plaque formation was reported for APPPS1 mice [19] compared to Tg2576 mice (35 vs. 3.40 week $^{-1} \mathrm{~mm}^{-3}$ ). Although median plaque growth rates were similar in both mouse models, individual plaque growth rates showed a big variance. In addition, plaque growth rates of neighboring plaques did not correlate. Combining both results, it is most likely that different conditions within the microenvironment of plaques are causal for the different growth rates. Such conditions could include $\mathrm{pH}$, ionic strength and hydrophobicity of the A $\beta$ peptide, as well as interactions with membranes [46-49]. Even though the analysis of a single animal is statistically not sufficient, the unique dataset containing a complete plaque growth kinetic further supports this idea. It highlights that large plaques were formed early during $A \beta$ accumulation and have the highest growth rates. This in turn suggests that plaques are first formed at sites where the best conditions exist.

In conclusion, the comprehensive plaque density and growth kinetics point to a three-stage model of $\beta$-amyloid accumulation (Figure 7). According to the kinetics of plaque volume three phases can be distinguished: (1) a cubic (2) a transition and (3) a saturation phase. Initially, a high concentration of $A \beta$ above the critical concentration leads to the formation of many new plaques (cubic phase). Later, the large number of plaques may serve as "dumps" for free $\mathrm{A} \beta$, so that its concentration gradually drops, causing the formation of fewer plaques during the transition phase, while existing plaques continue growing. In the saturation phase, single plaques show an overall slower growth due to the large number of plaques, while no new plaques are deposited, thus $A \beta$ production becomes rate-limiting. Furthermore, due to the same sigmoid-shaped characteristic of plaque accumulation in humans, albeit over one to two decades, such a model may help extrapolate observations from AD mouse models to the situation in humans, particularly with regards to pre-clinical testing of $A \beta$-lowering therapeutics $[7,13]$. In particular, the determination of plaque density kinetics may be more sensitive than analyzing plaque volume kinetics when evaluating anti-aggregation agents, since $\mathrm{A} \beta$ concentration is not rate-limiting to plaque growth in the early stage of amyloid deposition.

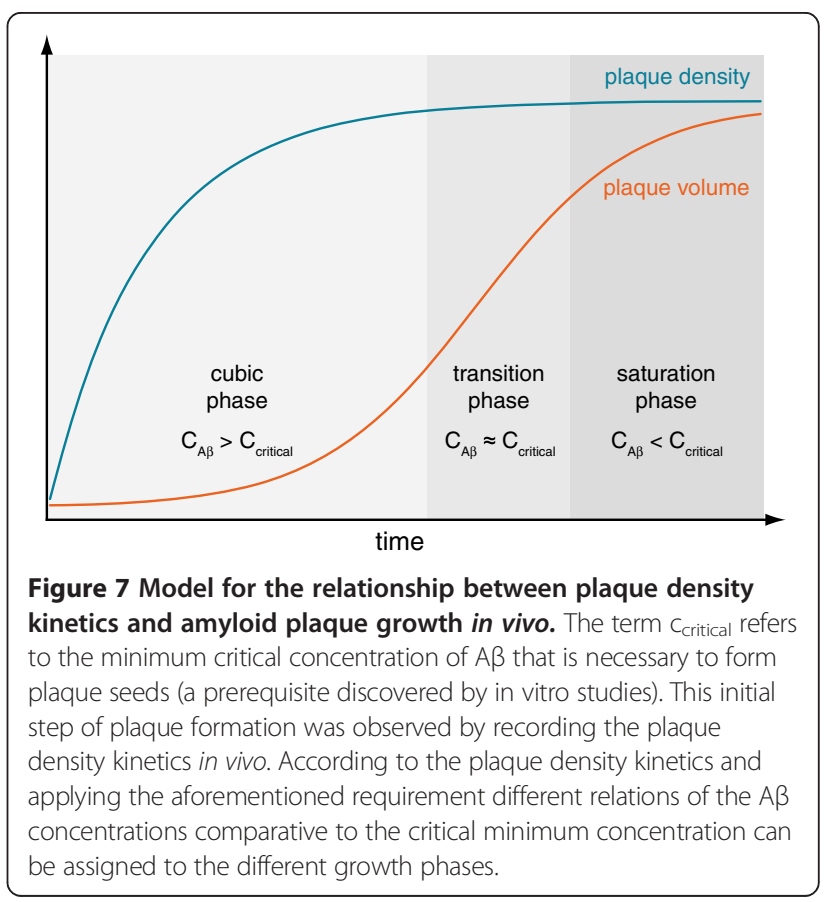




\section{Additional files}

Additional file 1: This video shows the complete plaque growth kinetic from 12 to $\mathbf{2 7 . 5}$ months of age (image data from Figure 1b). Data is displayed as 3D-volume rendered images. Big squares represent $100 \mu \mathrm{m}$.

Additional file 2: Figure S1. (a) Plaque volume data of two additional mice over 6 months. Mean plaque volumes were best fit with either a sigmoid function (mouse1: open triangles) or a cubic function (mouse2: open circles). Error bars show $95 \% \mathrm{Cl}$. (b) Kinetics of the plaque densities (dotted lines) and mean volumes (colored lines showing nonlinear fitted functions) over time for all 3 mice imaged at least over a period of 6 months. Vertical dotted lines indicate time points when plaque densities did not further increase. (c) Relationship of amyloid plaque load (integrated plaque volume/imaging volume) and plaque density for each imaged position. Linear regression was performed for each age cohort. The slopes were statistically significant different from zero (F-test). (d) Comparison of the plaque densities between the young cohort of the current study and another group of mice of a further study. Line and error bars display mean with $95 \% \mathrm{Cl}$. The means were not significant different (t-test). (e) Plaque density measured in APPPS1 mice at 4 months of age. Line and error bars display mean with $95 \% \mathrm{Cl}$. The equations were used for curve fitting.

\section{Competing interests}

The authors declare that they have no competing interests.

\section{Acknowledgements}

We thank Neville Vassallo (University of Malta) for proof-reading and valuable comments on the manuscript, Kevin Keppler for assistance with long-term imaging and Sonja Steinbach for animal care and genotyping. This work was supported by grants from the Deutsche Forschungsgemeinschaft (SFB 596, A13), the German Federal Ministry of Education and Research (Bundesministerium für Bildung und Forschung, 01GZ0713, 13 N9268), the German Federal Ministry of Economics and Technology (Bundesministerium für Wirtschaft und Technologie, 16IN0675) and the European Union (Neuro.GSK3, FP-7-223276).

\section{Author details}

${ }^{1}$ German Center for Neurodegenerative Diseases (DZNE),

Ludwig-Maximilians-University Munich, Feodor-Lynen-Str. 23, 81377

Munich, Germany. ${ }^{2}$ Center for Neuropathology, Ludwig-Maximilians-University Munich, Feodor-Lynen-Strasse 23, 81377 Munich, Germany. ${ }^{3}$ Munich Cluster of Systems Neurology (SyNergy), Ludwig-Maximilians-University Munich, Schillerstrasse 44, 80336 Munich, Germany. ${ }^{4}$ Clemens Schoepf-Institute for Organic Chemistry and Biochemistry, Technische Universität Darmstadt, Petersenstrasse 22, 64287 Darmstadt, Germany.

\section{Received: 12 March 2014 Accepted: 13 March 2014}

Published: 28 March 2014

\section{References}

1. Duyckaerts C, Delatour B, Potier M-C (2009) Classification and basic pathology of Alzheimer disease. Acta Neuropathol 118(1):5-36

2. Nalivaeva NN, Turner AJ (2013) The amyloid precursor protein: a biochemical enigma in brain development, function and disease. FEBS Lett 587(13):2046-2054, doi:10.1016/j.febslet.2013.05.010

3. Glenner GG, Wong CW (1984) Alzheimer's disease: initial report of the purification and characterization of a novel cerebrovascular amyloid protein. Biochem Biophys Res Commun 120(3):885-890

4. Haass C (2004) Take five-BACE and the $\gamma$-secretase quartet conduct Alzheimer's amyloid $\beta$-peptide generation. EMBO J 23(3):483-488

5. Hardy J, Allsop D (1991) Amyloid deposition as the central event in the aetiology of Alzheimer's disease. Trends Pharmacol Sci 12(10):383-388

6. Hardy J, Selkoe DJ (2002) The amyloid hypothesis of Alzheimer's disease: progress and problems on the road to therapeutics. Science 297(5580):353-356

7. Bateman RJ, Xiong C, Benzinger TLS, Fagan AM, Goate A, Fox NC, Marcus DS, Cairns NJ, Xie X, Blazey TM, Holtzman DM, Santacruz A, Buckles V, Oliver A, Moulder K, Aisen PS, Ghetti B, Klunk WE, McDade E, Martins RN, Masters CL, Mayeux R, Ringman JM, Rossor MN, Schofield PR, Sperling RA, Salloway
S, Morris JC, Network DIA (2012) Clinical and biomarker changes in dominantly inherited Alzheimer's disease. N Engl J Med 367(9):795-804

8. Hortschansky P, Schroeckh V, Christopeit T, Zandomeneghi G, Fändrich M (2005) The aggregation kinetics of Alzheimer's $\beta$-amyloid peptide is controlled by stochastic nucleation. Protein Sci 14(7):1753-1759

9. Hsiao K, Chapman P, Nilsen S, Eckman C, Harigaya Y, Younkin S, Yang F, Cole $G$ (1996) Correlative memory deficits, $A \beta$ elevation, and amyloid plaques in transgenic mice. Science 274(5284):99-102

10. Nordberg A (2004) PET imaging of amyloid in Alzheimer's disease. Lancet Neurol 3(9):519-527, doi:10.1016/S1474-4422(04)00853-1

11. Kang J, Lemaire HG, Unterbeck A, Salbaum JM, Masters CL, Grzeschik KH, Multhaup G, Beyreuther K, Müller-Hill B (1987) The precursor of Alzheimer's disease amyloid A4 protein resembles a cell-surface receptor. Nature 325 (6106):733-736

12. Burdick D, Soreghan B, Kwon M, Kosmoski J, Knauer M, Henschen A, Yates J, Cotman C, Glabe C (1992) Assembly and aggregation properties of synthetic Alzheimer's A4/ $\beta$ amyloid peptide analogs. J Biol Chem 267(1):546-554

13. Jack CR Jr, Wiste HJ, Lesnick TG, Weigand SD, Knopman DS, Vemuri P, Pankratz VS, Senjem ML, Gunter JL, Mielke MM, Lowe VJ, Boeve BF, Petersen RC (2013) Brain $\beta$-amyloid load approaches a plateau. Neurology 80(10):890-896, Doi:10.1212/WNL.0b013e3182840bbe

14. Jarrett JT, Lansbury JPT (1993) Seeding "one-dimensional crystallization" of amyloid: a pathogenic mechanism in Alzheimer's disease and scrapie? Cell 73(6):1055-1058

15. Liebscher S, Meyer-Luehmann M (2012) A peephole into the brain: Neuropathological features of Alzheimer's disease revealed by in vivo two-photon imaging. Front Psychiatry 3:26-26

16. Bittner T, Burgold S, Dorostkar MM, Fuhrmann M, Wegenast-Braun BM, Schmidt B, Kretzschmar H, Herms J (2012) Amyloid plaque formation precedes dendritic spine loss. Acta Neuropathol 124(6):797-807

17. Burgold S, Bittner T, Dorostkar MM, Kieser D, Fuhrmann M, Mitteregger G, Kretzschmar H, Schmidt B, Herms J (2011) In vivo multiphoton imaging reveals gradual growth of newborn amyloid plaques over weeks. Acta Neuropathol 121(3):327-335

18. Condello C, Schain A, Grutzendler J (2011) Multicolor time-stamp reveals the dynamics and toxicity of amyloid deposition. Sci Rep 1:19-19

19. Hefendehl JK, Wegenast-Braun BM, Liebig C, Eicke D, Milford D, Calhoun ME, Kohsaka S, Eichner M, Jucker M (2011) Long-term in vivo imaging of $\beta$-amyloid plaque appearance and growth in a mouse model of cerebral ß-amyloidosis. J Neurosci 31(2):624-629

20. Yan P, Bero AW, Cirrito JR, Xiao Q, Hu X, Wang Y, Gonzales E, Holtzman DM, Lee J-M (2009) Characterizing the Appearance and Growth of Amyloid Plaques in APP/PS1 Mice. J Neurosci 29(34):10706-10714

21. Meyer-Luehmann M, Spires-Jones TL, Prada C, Garcia-Alloza M, de Calignon A, Rozkalne A, Koenigsknecht-Talboo J, Holtzman DM, Bacskai BJ, Hyman BT (2008) Rapid appearance and local toxicity of amyloid- $\beta$ plaques in a mouse model of Alzheimer's disease. Nature 451(7179):720-724

22. Christie RH, Bacskai BJ, Zipfel WR, Williams RM, Kajdasz ST, Webb WW, Hyman BT (2001) Growth arrest of individual senile plaques in a model of Alzheimer's disease observed by in vivo multiphoton microscopy. J Neurosci 21(3):858-864

23. Radde R, Bolmont T, Kaeser SA, Coomaraswamy J, Lindau D, Stoltze L, Calhoun ME, Jäggi F, Wolburg H, Gengler S, Haass C, Ghetti B, Czech C, Hölscher C, Mathews PM, Jucker M (2006) Aß42-driven cerebral amyloidosis in transgenic mice reveals early and robust pathology. EMBO Rep 7(9):940-946

24. Bittner T, Fuhrmann M, Burgold S, Jung CK, Volbracht C, Steiner $H$, Mitteregger G, Kretzschmar HA, Haass C, Herms J (2009) $\gamma$-secretase inhibition reduces spine density in vivo via an amyloid precursor proteindependent pathway. J Neurosci 29(33):10405-10409, doi:10.1523/JNEUROSCI.2288-09.2009

25. Bittner T, Fuhrmann M, Burgold S, Ochs SM, Hoffmann N, Mitteregger G, Kretzschmar H, LaFerla FM, Herms J (2010) Multiple events lead to dendritic spine loss in triple transgenic Alzheimer's disease mice. PLoS One 5(11):e15477, doi:10.1371/journal.pone.0015477

26. Fuhrmann M, Bittner T, Jung CK, Burgold S, Page RM, Mitteregger G, Haass C, LaFerla FM, Kretzschmar H, Herms J (2010) Microglial Cx3cr1 knockout prevents neuron loss in a mouse model of Alzheimer's disease. Nat Neurosci 13(4):411-413, doi:10.1038/nn.2511

27. Fuhrmann M, Mitteregger G, Kretzschmar H, Herms J (2007) Dendritic pathology in prion disease starts at the synaptic spine. J Neurosci 27(23):6224-6233 
28. Holtmaat A, Bonhoeffer T, Chow DK, Chuckowree J, Paola VD, Hofer SB, Hübener M, Keck T, Knott G, Lee W-CA, Mostany R, Mrsic-Flogel TD, Nedivi E, Portera-Cailliau C, Svoboda K, Trachtenberg JT, Wilbrecht L (2009) Longterm, high-resolution imaging in the mouse neocortex through a chronic cranial window. Nat Protoc 4(8):1128-1144

29. Klunk WE, Bacskai BJ, Mathis CA, Kajdasz ST, McLellan ME, Frosch MP, Debnath ML, Holt DP, Wang Y, Hyman BT (2002) Imaging A $\beta$ plaques in living transgenic mice with multiphoton microscopy and methoxy-X04, a systemically administered Congo red derivative. J Neuropathol Exp Neurol 61(9):797-805

30. Das P, Verbeeck C, Minter L, Chakrabarty P, Felsenstein K, Kukar T, Maharvi G, Fauq A, Osborne BA, Golde TE (2012) Transient pharmacologic lowering of $A \beta$ production prior to deposition results in sustained reduction of amyloid plaque pathology. Mol Neurodegener 7(39):1-9

31. Crowe SE, Ellis-Davies GC (2013) In vivo characterization of a bigenic fluorescent mouse model of Alzheimer's disease with neurodegeneration. J Comp Neurol 521(10):2181-2194, doi:10.1002/cne.23306

32. Hyman BT, West HL, Rebeck GW, Buldyrev SV, Mantegna RN, Ukleja M, Havlin S, Stanley HE (1995) Quantitative analysis of senile plaques in Alzheimer disease: observation of log-normal size distribution and molecular epidemiology of differences associated with apolipoprotein $\mathrm{E}$ genotype and trisomy 21 (Down syndrome). Proc Natl Acad Sci U S A 92(8):3586-3590

33. Bolmont T, Haiss F, Eicke D, Radde R, Mathis CA, Klunk WE, Kohsaka S, Jucker M, Calhoun ME (2008) Dynamics of the microglial/amyloid interaction indicate a role in plaque maintenance. J Neurosci 28(16):4283-4292, doi:10.1523/jneurosci.4814-07.2008

34. McCarter JF, Liebscher S, Bachhuber T, Abou-Ajram C, Hubener M, Hyman BT, Haass C, Meyer-Luehmann M (2013) Clustering of plaques contributes to plaque growth in a mouse model of Alzheimer's disease. Acta Neuropathol 126(2):179-188, doi:10.1007/s00401-013-1137-2

35. Mathis CA, Wang Y, Holt DP, Huang GF, Debnath ML, Klunk WE (2003) Synthesis and evaluation of 11C-labeled 6-substituted 2-arylbenzothiazoles as amyloid imaging agents. J Med Chem 46(13):2740-2754, doi:10.1021/jm030026b

36. Mori T, Maeda J, Shimada H, Higuchi M, Shinotoh H, Ueno S, Suhara T (2012) Molecular imaging of dementia. Psychogeriatrics 12(2):106-114, doi:10.1111/j.1479-8301.2012.00409.x

37. Villain $N$, Chetelat $G$, Grassiot $B$, Bourgeat $P$, Jones $G$, Ellis KA, Ames $D$, Martins RN, Eustache F, Salvado O, Masters CL, Rowe CC, Villemagne VL (2012) Regional dynamics of amyloid- $\beta$ deposition in healthy elderly, mild cognitive impairment and Alzheimer's disease: a voxelwise PiB-PET longitudinal study. Brain 135(Pt 7):2126-2139, doi:10.1093/brain/aws125

38. Harper JD, Lansbury PT (1997) Models of amyloid seeding in Alzheimer's disease and scrapie: mechanistic truths and physiological consequences of the time-dependent solubility of amyloid proteins. Annu Rev Biochem 66:385-407

39. Hellstrand E, Boland B, Walsh DM, Linse S (2010) Amyloid $\beta$-Protein Aggregation Produces Highly Reproducible Kinetic Data and Occurs by a TwoPhase Process. ACS Chem Neurosci 1(1):13-18

40. Cirrito JR, May PC, O'Dell MA, Taylor JW, Parsadanian M, Cramer JW, Audia JE, Nissen JS, Bales KR, Paul SM, DeMattos RB, Holtzman DM (2003) In vivo assessment of brain interstitial fluid with microdialysis reveals plaqueassociated changes in amyloid- $\beta$ metabolism and half-life. J Neurosci 23 (26):8844-8853

41. DeMattos RB, Bales KR, Parsadanian M, O'Dell MA, Foss EM, Paul SM, Holtzman DM (2002) Plaque-associated disruption of CSF and plasma amyloid- $\beta$ (A $A$ ) equilibrium in a mouse model of Alzheimer's disease. J Neurochem 81(2):229-236

42. Taconic Biochemical Characterization Alzheimer's Disease Models. http://www taconic.com/1349. (Accessed 10/04/2014)

43. Cairns NJ, Ikonomovic MD, Benzinger T, Storandt M, Fagan AM, Shah AR, Reinwald LT, Carter D, Felton A, Holtzman DM, Mintun MA, Klunk WE, Morris JC (2009) Absence of Pittsburgh compound B detection of cerebral amyloid beta in a patient with clinical, cognitive, and cerebrospinal fluid markers of Alzheimer disease: a case report. Arch Neurol 66(12):1557-1562, doi:10.1001/archneurol.2009.279

44. Ikonomovic MD, Klunk WE, Abrahamson EE, Mathis CA, Price JC, Tsopelas ND, Lopresti BJ, Ziolko S, Bi W, Paljug WR, Debnath ML, Hope CE, Isanski BA, Hamilton RL, DeKosky ST (2008) Post-mortem correlates of in vivo PiB-PET amyloid imaging in a typical case of Alzheimer's disease. Brain 131(Pt 6):1630-1645, doi:10.1093/brain/awn016
45. Lomakin A, Chung DS, Benedek GB, Kirschner DA, Teplow DB (1996) On the nucleation and growth of amyloid $\beta$-protein fibrils: detection of nuclei and quantitation of rate constants. Proc Natl Acad Sci U S A 93(3):1125-1129

46. Chiti F, Stefani M, Taddei N, Ramponi G, Dobson CM (2003) Rationalization of the effects of mutations on peptide and protein aggregation rates. Nature 424(6950):805-808

47. DuBay KF, Pawar AP, Chiti F, Zurdo J, Dobson CM, Vendruscolo M (2004) Prediction of the absolute aggregation rates of amyloidogenic polypeptide chains. J Mol Biol 341(5):1317-1326

48. Esler WP, Stimson ER, Ghilardi JR, Vinters HV, Lee JP, Mantyh PW, Maggio JE (1996) In vitro growth of Alzheimer's disease $\beta$-amyloid plaques displays first-order kinetics. Biochemistry 35(3):749-757

49. Terzi E, Hölzemann G, Seelig J (1995) Self-association of $\beta$-amyloid peptide (1-40) in solution and binding to lipid membranes. J Mol Biol 252 (5):633-642

doi:10.1186/2051-5960-2-30

Cite this article as: Burgold et al:: In vivo imaging reveals sigmoidal growth kinetic of $\beta$-amyloid plaques. Acta Neuropathologica Communications 2014 2:30.

\section{Submit your next manuscript to BioMed Central and take full advantage of:}

- Convenient online submission

- Thorough peer review

- No space constraints or color figure charges

- Immediate publication on acceptance

- Inclusion in PubMed, CAS, Scopus and Google Scholar

- Research which is freely available for redistribution 